\title{
FATORES SOCIAIS E FREQÜÊNCIA DE EMPRÉSTIMOS DO PORTUGUÊS NO JAPONÊS FALADO PELOS IMIGRANTES NO BRASIL - O CASO DO DISTRITO FEDERAL
}

RESUMO: Neste estudo, tratamos o empréstimo lexical como uma das características mais marcantes observadas na língua falada dos isseis no Brasil, fenômeno que surge no estágio inicial do contato lingüístico. Para a pesquisa de campo do presente estudo, que foi realizada em forma de entrevista com isseis, foi escolhido o Distrito Federal. Com o objetivo de apreender acerca da interação entre os fatores sociais e frequiência, apresentamos um levantamento estatístico da frequiência de uso dos empréstimos à luz de fatores sociais.

ABSTRACT: This study deals with lexical borrowing as one of the most crucial characteristics observed in the spoken language of the isseis in Brasil, a phenomenon that appears in the initial stages of linguistic contact. The data for this study was collected in the form of interviews with isseis, and the area of study was the Federal District. The objective was to gain insight into the integration between social factors and frequency of borrowing. This study presents statistical data for frequency of borrowing in light of social factors.

PALAVRAS-CHAVE: empréstimo lexical, fatores sociais, freqüência de empréstimos, issei

KEYWORDS: lexical borrowing, social factors, frequency of borrowing, issei

Os imigrantes japoneses do Brasil criaram um tipo de japonês com características peculiares de tal modo que nos permite chamá-lo de uma variedade da língua japonesa. Essa variedade tem, como uma das características mais marcantes, o uso do empréstimo 
lexical do português brasileiro resultante do contato lingüístico que eles tiveram com essa língua ao chegarem no Brasil como imigrantes.

A língua é utilizada dentro de um contexto social. A variedade de língua denominada empréstimo é provocada não somente pelos fatores puramente inerentes à língua, como também, pela interação entre esses e os fatores sociais como sexo, idade, classe social, entre outros. A freqüência do empréstimo do português no japonês falado pelos isseis ${ }^{1}$ é determinada também pelo parâmetro do tipo, seus fatores sociais dos mais variados. No presente estudo, foi realizada a análise quantitativa que apreenda a inter-ação entre esse tipo de condições lingüísticas (frequêencia do empréstimo) e condições sociais. Como outros estudos anteriores a este da mesma natureza, podemos citar os realizados por Poplack, Sankoff e Miller (1988) sobre a freqüência de empréstimo do inglês na comunidade francófona do Canadá.

Os dados utilizados no presente trabalho é o resultado da comparação da frequiência de empréstimo do português que ocorre na gravação, de 15 minutos cada, de entrevistas feitas com 70 informantes no Distrito Federal, tendo um único tema e uma só entrevistadora. Para evitar o desequilíbrio das restrições sociais, na seleção dos informantes, o método adotado não foi só o de amostragem aleatória mas também o de amostragem por julgamento. Como fatores sociais foram estabelecidos: sexo, idade, ano de chegada ao Brasil, idade que tinha no momento em que chegou ao Brasil, anos de permanência no Brasil, profissão, escolaridade, domínio da língua portuguesa, proporção de uso do japonês no cotidiano, vezes e o tempo que esteve no Japão após a sua vinda ao Brasil. A média de ocorrência do empréstimo por informante foi calculada por cada um destes fatores e o resultado encontra-se nos Gráficos 1 10 (cf. anexo). A ocorrência média de empréstimo por pessoa, neste levantamento feito através de entrevistas, foi aproximadamente 8 vezes. Seu intervalo com $95 \%$ de confiança é de 5 a 11 vezes. Apresentamos a seguir, na ordem do gráfico, a nossa análise de acordo com cada fator social.

\section{Sexo}

O quadro de informantes foi composto de 35 homens e 35 mulheres, em uma proporção de $50 \%$ por sexo (cf. Tabela 1 ). As mulheres apresentam uma freqüência ligeiramente mais alta de empréstimo.

Tabela 1

Distribuição dos Informantes por Sexo

\begin{tabular}{|c|c|}
\hline Feminino & Masculino \\
\hline 35 & 35 \\
$(50 \%)$ & $(50 \%)$ \\
\hline
\end{tabular}

1. Issei: significa, literalmente, "primeira geração" Denominação dada ao imigrante japonês. 


\section{Idade}

Tendo em vista que o movimento imigratório de japoneses ao Brasil diminuiu consideravelmente a partir dos anos 80 , a maior parte dos isseis tem hoje idade superior a 50 anos. Quanto aos informantes do presente estudo, a faixa etária distribui-se como segue:

Tabela 2

Distribuição dos Informantes por Idade

\begin{tabular}{|c|c|c|c|c|}
\hline$\sim 49$ anos & $50 \sim 59$ anos & $60 \sim 69$ anos & $70 \sim 79$ anos & 80 anos \\
\hline 7 & 18 & 221 & 20 & 4 \\
$(10,0 \%)$ & $(25,7 \%)$ & $(30,0 \%)$ & $(28,6 \%)$ & $(5,7 \%)$ \\
\hline
\end{tabular}

Duas hipóteses foram aventadas ao pensarmos no fator idade:

1. aumento da freqüência, à medida que diminui a faixa etária, pois maior seria a capacidade de absorção da língua estrangeira, no caso o português do Brasil;

2. aumento da freqüência de empréstimos nas faixas e idade mais elevadas, supostamente de pessoas com mais tempo de permanência no Brasil, e, conseqüentemente, com mais tempo de contato com a língua portuguesa do Brasil.

Entretanto, no que concerne à correlação entre idade e frequiência de empréstimos (cf. Gráfico 2), não apenas deixou de ocorrer uma elevação da curva à direita, como as menores freqüências de empréstimo ocorreram nas faixas etárias extremas (até 40 anos e mais de 80 anos), que sucederam as menores freqüências de empréstimo. A curva apresenta-se irregular, apontando maior frequiência nas faixas de 50 a 59 anos (14 ocorrências).

Explicação viável para esses dados é a de que as pessoas com idade superior a 80 anos tenham usado predominantemente a língua japonesa durante a sua vida no Brasil, em razão de terem imigrado para o País com idade mais avançada, o que lhes prejudicou a aquisição e o domínio da variante brasileira. A maior parte dos isseis na faixa etária de 40 anos veio para o Brasil na condição de jun-issei ${ }^{2}$ e, devido à falta de confiança no japonês que falam, monitoram-se para usar o japonês padrão, principalmente quando em situação de fala formal, como no caso da entrevista com uma japonesa vinda recentemente do Japão. Esse evento leva-os a ter cuidado para não recorrerem a empréstimos do português brasileiro. Com relação às pessoas na faixa etária de 50 anos, podemos afirmar que, pelo seu tempo de permanência no Brasil, dominam mais o português e usam-no com frequiência, o que se reflete no alto índice de empréstimos encontrados nos dados que lhes são pertinentes.

2. Jun-issei: denominação dada ao issei vindo ao Brasil ainda criança. 


\section{Ano de Ingresso no Brasil}

Dividimos os informantes em grupos de imigrantes anteriores e posteriores à Segunda Guerra Mundial, para verificarmos se existe ou não mudança em relação ao uso de empréstimos entre os isseis que vieram para o Brasil nesses períodos. A imigração japonesa no Brasil sofreu uma interrupção de pouco mais de uma década, intercalando o período anterior e o posterior à Segunda Guerra. A característica mais marcante, que distingue o primeiro grupo de imigrantes (anterior à Segunda Guerra) do segundo (posterior à Segunda Guerra) é a finalidade da sua vinda. Enquanto o grupo de imigrantes de antes da Segunda Guerra visava quase que exclusivamente à exploração agrícola, o grupo que imigrou após a Segunda Guerra possuía objetivos mais diversificados. Um dos exemplos é a imigração de técnicos para dedicarem-se à indústria.

O período após a Segunda Guerra Mundial foi dividido arbitrariamente em primeiros 10 anos e o restante para que pudéssemos observar a existência ou não da diferença em relação ao uso da linguagem entre os informantes desses dois grupos. Como o número de imigrantes foi extremamente reduzido a partir de 1980, não achamos necessário fazermos uma nova subdivisão.

Tabela 3

Distribuição dos Informantes por Ano de Ingresso no Brasil

\begin{tabular}{|c|c|c|}
\hline Antes da Segunda Guerra Mundial & \multicolumn{2}{|c|}{ Pós-Guerra } \\
\hline 1925 a 1939 & 1950 a 1959 & $1960 \sim$ \\
13 & 38 & 19 \\
$(18,6 \%)$ & $(54,3 \%)$ & $(27,1 \%)$ \\
\hline
\end{tabular}

A época da chegada no Brasil não se mostrou significativa na freqüência de empréstimos. Essa variável será considerada nas nossas ponderações sobre a correlação do empréstimo com o tempo de permanência no Brasil.

\section{Idade ao Ingressar no Brasil}

A idade dos informantes no momento da sua chegada no Brasil deve ser considerada juntamente com a questão de aquisição da linguagem. Segundo Nakamura, Kaneko e Kikuchi (1997), as crianças geralmente adquirem o domínio de grande parte da gramática aos 5 ou 6 anos, completando essa aquisição aos 14 ou 15 anos. Por isso, nesse quesito, na divisão das faixas etárias de entrada no Brasil levamos em conta a sua correlação com o processo de aquisição geral da língua: de 0 a 5 anos, período de aquisição da língua materna; de 6 a 14 anos, período importante para a aquisição geral da linguagem, e de 15 a 19 anos, quando já há domínio da primeira língua mas ainda apresenta facilidade para a aquisição da segunda, seguidos dos grupos das faixas etárias de 20,30 e acima de 40 anos. 
Tabela 4

Distribuição dos Informantes por Idade ao Ingressar no Brasil

\begin{tabular}{|c|c|c|c|c|c|}
\hline $0 \sim 5$ anos & $6 \sim 14$ anos & $15 \sim 19$ anos & $20 \sim 29$ anos & $30 \sim 39$ anos & 40 anos $~$ \\
\hline $\begin{array}{c}5 \\
(7,1 \%)\end{array}$ & 15 & 8 & 29 & 10 & 3 \\
$(21,4 \%)$ & $(11,4 \%)$ & $(41,4 \%)$ & $(14,3 \%)$ & $(4,3 \%)$ \\
\hline
\end{tabular}

A idade de entrada no Brasil está claramente relacionada com questões de bilingüismo em termos de domínio do português do Brasil e do japonês. Os jun-issei vindos para o Brasil com a idade de 0 a 14 anos, embora em alguns casos apresentem problemas quanto à parte fonológica, em geral apresentam um bom domínio do português brasileiro e baixa porcentagem de uso do japonês, revelando, na maioria das vezes, deficiência no domínio do japonês. Como exceção, há aqueles que, mesmo sendo junissei, foram forçados a levar uma vida praticamente restrita ao uso do japonês nas colônias agrícolas. Esses apresentam uma alta porcentagem de uso do japonês e um baixo domínio da língua portuguesa do Brasil. $\mathrm{O}$ resultado demonstrado no gráfico 4 revela que, ao contrário do esperado, os jun-issei chegados no Brasil em idade de aquisição da primeira língua ( 0 a 5 ) e em idade importante para a sua aquisição (6 a 14) apresentam uma baixa freqüência de empréstimos. Como mencionado com referência ao fator idade, isso acontece porque, na maioria das vezes, a primeira língua dos jun-issei é o português brasileiro. Esses imigrantes monitoram o vernáculo referente à língua japonesa padrão quando falam o japonês, registrando, assim, baixo uso de empréstimos. Mesmo tendo passado a infância em um núcleo de colonização e tendo o japonês como língua materna, ao começarem a freqüentar a escola de ensino formal, o português passou a ser para a maioria deles a língua dominante. Dessarte, a sua freqüência de uso de empréstimos é igualmente baixa.

Quanto aos informantes isseis que possuíam idade superior a 40 anos ao imigrarem e que apresentam baixa recorrência a empréstimos, podemos dizer que lhes ocorreu a fossilização ${ }^{3}$, no que tange à aquisição da segunda língua, devido à consolidação do seu japonês. Faltou-lhes flexibilidade para aceitar facilmente outras línguas e daí a pouca mistura com o português brasileiro.

O que cogitamos ser a causa do índice mais elevado da freqüência no uso de empréstimos pelos isseis que vieram para o Brasil na faixa etária de 15 a 19 anos é a sua autoconfiança. Esses informantes tiveram muitas oportunidades de contato com o português do Brasil e dessa língua possuem bons conhecimentos, além de bom domínio do japonês. Assim sendo, não manifestam resistência ao uso de empréstimos, o que, naturalmente, faz com que aumentem a freqüência da sua utilização.

Em relação ao sensível aumento de uso de empréstimos pelos isseis na faixa etária de 30 a 39 anos, o fator não chega a ser significativo a ponto de pensarmos que para isso há alguma razão especial.

3. Fossilização (fossilization): a aprendizagem fica estagnada na etapa intermediária da aquisição da segunda língua, devido à vontade ou não de aprender, volume do input, necessidade em relação a essa nova língua e outros fatores. 
No que se refere a essas duas faixas etárias comparadas à que apresentou maior frequiência de empréstimos, cogitamos de que seja o maior domínio do japonês pelos isseis de 30 a 39 anos, em detrimento da sua proficiência no português do Brasil, o que lhes dificulta a transição de uma língua para a outra. A oscilação pode-se dar em decorrência de terem ou não incluídos os empréstimos na vida sua diária, independentemente do domínio dessa ou daquela língua.

\section{Tempo de Permanência no Brasil}

Os informantes foram divididos em grupos, para cada 10 anos de permanência no Brasil. Chamamos a atenção para a faixa de 50 a 59 anos que, por estar compreendendo os anos da Segunda Grande Guerra, apresenta apenas um informante. A metade (50\%) tem de 40 a 49 anos de tempo em solo brasileiro.

Tabela 5

Distribuição dos Informantes por Tempo de Permanência no Brasil

\begin{tabular}{|c|c|c|c|c|c|}
\hline$\sim 29$ anos & $30 \sim 39$ anos & $40 \sim 49$ anos & $50 \sim 59$ anos & $60 \sim 69$ anos & 70 anos $~$ \\
\hline 3 & 19 & 35 & 1 & 10 & 2 \\
$(4,3 \%)$ & $(27,1 \%)$ & $(50,0 \%)$ & $(1,4 \%)$ & $(14,3 \%)$ & $(2,9 \%)$ \\
\hline
\end{tabular}

Como acontece com os informantes com permanência no Brasil inferior a 29 anos, como demonstrado no Gráfico 5, a nossa hipótese é a de que quando o tempo de permanência for menor, menor também será a frequiência de uso de empréstimos. Não obstante isso e como a maioria dos isseis já tem mais de 30 anos de permanência em solo brasileiro, não há aumento de frequiência proporcional ao tempo no Brasil, sendo o número praticamente estável.

Em relação a dois informantes com mais de 70 anos no Brasil, supomos que, por terem vindo ao Brasil ainda na infância, estão conscientes da sua deficiência no domínio do japonês e, conseqüentemente, evitam, de modo monitorado, o uso do empréstimo.

\section{Profissão}

O maior número de isseis (cerca de 95\%) dedica-se à agricultura, sendo ínfima a parcela de profissionais qualificados e dos que atuam em outras profissões. Dessarte, neste estudo, distinguimos as profissões nas três categorias mais comuns entre os isseis no Distrito Federal - agricultores, comerciantes e profissionais qualificados. Ressalvamos que entendemos por profissão qualificada aquela que exige instrução e conhecimento específico da área de trabalho, como advogados, tradutores, funcionários da Embaixada do Japão e professores, entre outros.

Arrolamos informantes também em uma quarta categoria, que intitulamos outros, formada pelos que não se enquadravam nas demais, como as donas-de-casa, os 
profissionais autônomos e sem qualificação específica. E classificamos os informantes aposentados consoante a profissão que exerciam quando trabalhavam.

Tabela 6

Distribuição dos Informantes por Profissão

\begin{tabular}{|c|c|c|c|}
\hline Agricultores & Comerciantes & $\begin{array}{c}\text { Profissionais } \\
\text { Qualificados }\end{array}$ & Outros \\
\hline 36 & 10 & 10 & 14 \\
$(14,3 \%)$ & $(51,4 \%)$ & $(14,3 \%)$ & $(20,0 \%)$ \\
\hline
\end{tabular}

O Gráfico 6 evidencia que o uso do empréstimo é mais freqüente entre as pessoas que atuam no comércio e menos freqüente entre os profissionais qualificados. Como causa disso, podemos dizer que o que ocorre entre os comerciantes é o fato de que a maioria pertence à categoria de jun-issei com conhecimento do português, além de usar o português com freqüência, por lidar com fregueses sem ascendência japonesa. No momento de falar o japonês, devido ao hábito adquirido de falar o português brasileiro, esses isseis acabam recorrendo a empréstimos desta língua.

Contudo, entre os profissionais com qualificação específica encontram-se advogados que atuam em casos que envolvem negociações entre o Brasil e o Japão, tradutores de japonês-português, funcionários graduados da Embaixada do Japão e professores de língua japonesa para alunos brasileiros. Talvez, a razão que leve esses profissionais a apresentarem baixa incidência de uso de empréstimos seja o seu alto grau de consciência lingüística, em razão de suas necessidades profissionais, do uso simultâneo das duas línguas envolvidas e a sua capacidade de distingui-las sem misturá-las.

\section{Escolaridade}

Realizamos a divisão em grupos tendo como referência o nível de escolaridade mais alto atingido pelos informantes, sem distinguirmos se esses estudos foram realizados no Brasil ou no Japão. Essa distinção obedeceu aos níveis de escolaridade do Japão que, à época da frequiência desses imigrantes à escola no Brasil, quando o faziam, seguiam mais ou menos os mesmos níveis da escola brasileira.

Tabela 7

Distribuição dos Informantes por Escolaridade

\begin{tabular}{|c|c|c|c|}
\hline Primário & Ginásio & Colegial & Superior \\
\hline 9 & 27 & 23 & 11 \\
$(12,9 \%)$ & $(36,6 \%)$ & $(32,9 \%)$ & $(15,7 \%)$ \\
\hline
\end{tabular}

O Gráfico 7 revela que não há diferença significativa entre a freqüência de uso de empréstimos pelos informantes de escolaridade primária, secundária e colegial. 
Não obstante isso, a freqüência torna-se surpreendentemente mais baixa para os informantes que possuem o nível superior. Assim como ocorreu em relação ao fator profissão, isso provavelmente deve-se ao seu alto nível de consciência do uso da linguagem, em razão da sua intelectualidade, traduzida em forma de alto nível de consciência no uso diferenciado das línguas em questão. Aliás, profissão e escolaridade complementam-se, considerando-se que a maior parte dos informantes com nível superior exercem profissões, aqui classificadas como qualificados: 7 , entre 11, possuem curso superior.

\section{Proficiência em Português}

Neste quesito, cumpre-nos relatar que a proficiência no português foi medida pelo próprio informante e por nós, como entrevistadora, não tendo sido seguido nenhum critério objetivo como teste. Entre as quatro habilidades da língua, as da leitura e da escrita não foram incluídas nessa classificação. Consideramos apenas as de ouvir e falar, por entendermos que estão diretamente relacionadas ao empréstimo que ocorre na língua falada.

A maioria dos entrevistados julga possuir um desempenho fraco ou médio no português brasileiro $(55,7 \%)$, com destaque para um desempenho excelente $(24,3 \%)$.

Tabela 8

Distribuição dos Informantes pela Proficiência em Português

\begin{tabular}{|l|c|c|c|c|c|}
\hline \multicolumn{1}{|c|}{ Nível } & Nulo & Fraco & Médio & Bom & Excelente \\
\hline Compreensão & Nula ou fraca & Fraca ou média & Média & Boa & Boa \\
\hline Expressão Oral & Nula & Fraca & Média & Média & Boa \\
\hline & 8 & 15 & 24 & 6 & 17 \\
& $(11,4 \%)$ & $(21,4 \%)$ & $(34,3 \%)$ & $(8,6 \%)$ & $(24,3 \%)$ \\
\hline
\end{tabular}

Na correlação entre a proficiência no português e a freqüência de uso de empréstimos, percebemos um aumento gradativo na freqüência de uso conforme aumenta o grau de proficiência. A curva não é acentuada até o nível médio de proficiência, ocorrendo um salto entre esse e o nível bom para, em seguida, cair consideravelmente no nível excelente. Centrando as nossas considerações nessas duas categorias, a baixa freqüência de uso de empréstimos no nível excelente de proficiência do português brasileiro torna a corroborar a nossa hipótese de que as pessoas que possuem um bom domínio do português do Brasil possuem maior consciência lingüística e maior capacidade de usar as duas línguas diferentemente.

Com relação às pessoas com nível médio de proficiência no português brasileiro e que apresentaram a maior incidência de empréstimos, podemos dizer que são as que praticam efetivamente a "língua geral", a que nos referimos anteriormente, em que as interferências são reciprocamente mais fáceis de ocorrer. 


\section{Proporção da Língua Japonesa na Vida Diária}

A informação sobre a proporção ocupada pela língua japonesa na vida diária dos isseis foi-nos revelada pelos próprios informantes, considerando o seu uso em diversos ambientes tais como o lar, o trabalho, com os vizinhos etc.

Tabela 9-A

Distribuição dos Informantes por Proporção da Língua Japonesa na Vida Diária

\begin{tabular}{|c|c|c|c|c|}
\hline $\begin{array}{c}\text { Predomínio } \\
\text { Japonês } \\
90 \%\end{array}$ & $\begin{array}{c}\text { Japonês }> \\
\text { Português } \\
60 \sim 89 \%\end{array}$ & $\begin{array}{c}\text { Japonês }= \\
\text { Português } \\
50 \%\end{array}$ & $\begin{array}{c}\text { Japonês < } \\
\text { Português } \\
20 \sim 49 \%\end{array}$ & $\begin{array}{c}\text { Predomínio } \\
\text { Português } \\
\text { Menos de 19\% }\end{array}$ \\
\hline 22 & 23 & 10 & 11 & 4 \\
$(31,4 \%)$ & $(32,9 \%)$ & $(14,3 \%)$ & $(15,7 \%)$ & $(5,7 \%)$ \\
\hline
\end{tabular}

Na correlação dessa variável com a frequiência de empréstimos, verificamos que, como era previsto, há uma tendência a aumentar a ocorrência de empréstimos na medida em que, cotidianamente, diminui o uso do japonês e aumenta o do português do Brasil. Todavia, a curva que se mantém ascendente até o uso de "japonês < português" (cf. Gráfico 9-A) sofre uma quebra no grupo dos que usam predominantemente o português no dia-a-dia.

Tal fato remete-nos ao que constatamos quanto ao fator profissão: os profissionais qualificados apresentaram a menor taxa de empréstimos do português no japonês que falam, devido, provavelmente, à necessidade que a própria profissão impõe de um uso distinto de ambas as línguas. Há uma clara consciência desses profissionais, não só do uso de uma língua e da outra, como também da distinção do seu uso diglóssico.

Partindo, pois, do pressuposto de que esses informantes, devido à sua especificidade, poderiam modificar o quadro geral dos dados, realizamos um novo levantamento, excluindo os 10 profissionais qualificados do corpus, obtendo a distribuição seguinte:

Tabela 9-B

Distribuição dos Informantes por Proporção da Língua Japonesa na Vida Diária

\begin{tabular}{|c|c|c|c|c|}
\hline $\begin{array}{c}\text { Predomínio } \\
\text { Japonês } \\
90 \%\end{array}$ & $\begin{array}{c}\text { Japonês }> \\
\text { Português } \\
60 \sim 89 \%\end{array}$ & $\begin{array}{c}\text { Japonês }= \\
\text { Portugês } \\
50 \%\end{array}$ & $\begin{array}{c}\text { Japonês < } \\
\text { Português } \\
20 \sim 49 \%\end{array}$ & $\begin{array}{c}\text { Predomínio } \\
\text { Português } \\
\text { Menos de 19\% }\end{array}$ \\
\hline 22 & 20 & 7 & 7 & 4 \\
$(36,7 \%)$ & $(33,3 \%)$ & $(11,7 \%)$ & $(11,7 \%)$ & $(6,7 \%)$ \\
\hline
\end{tabular}

Assim sendo, no Gráfico 9-B, a inclinação da linha de tendência fica mais acentuada em relação à linha de tendência do Gráfico 9-A e evidencia-se o fato de que o empréstimo aumenta de frequiência à medida que vai diminuindo o uso do japonês $\mathrm{e}$ aumentando o uso do português. Porém, e novamente, a linha de tendência dos 
informantes que pertencem ao grupo que praticamente só usam o português no seu cotidiano e que, por isso, deveriam apresentar o índice mais alto de uso do empréstimo chama a nossa atenção. Ao contrário do que esperávamos, há uma diminuição drástica na frequiência de uso de empréstimos. Tal dado leva-nos a supor que, por esses isseis usarem quase que exclusivamente o português no seu dia-a-dia, independentemente da sua profissão, quando se vêem diante de uma situação em que é exigido o uso do japonês esforçam-se para usar o japonês padrão, evitando conscientemente o uso do português.

A curva mais acentuada da linha do Gráfico 9-B em relação à linha do Gráfico 9-A leva-nos a concluir que o uso do português influencia mais do que a profissão na ocorrência de empréstimos. Inversamente, as causas de menor uso de entréstimos estão mais relacionadas com o fator "profissionais qualificados" do que o fator "pouco uso do japonês"

\section{Permanência Temporária no Japão}

Dos setenta informantes, 60 possuem a experiência do retorno temporário ao Japão, seja como visitantes ou como trabalhadores temporários (dekassegui). Apenas 10 dos isseis entrevistados jamais retornaram ao Japão.

Realizamos a análise desses retornos temporários, dividindo-os em relação ao tempo de permanência no Japão e ao número de visitas.

Tabela 10-A

Distribuição dos Informantes por Tempo de Visitas ao Japão

\begin{tabular}{|c|c|c|c|}
\hline 0 & $\sim 6$ meses & 6 meses $\sim 1$ ano & 1 ano $\sim$ \\
\hline 11 & 37 & 11 & 11 \\
$(15,7 \%)$ & $(52,9 \%)$ & $(15,7 \%)$ & $(15,7 \%)$ \\
\hline
\end{tabular}

Tabela 10-B

Distribuição dos Informantes pelo Número de Visitas ao Japão

\begin{tabular}{|c|c|c|c|c|c|}
\hline 0 vezes & 1 vez & 2 vezes & 3 vezes & 4 vezes & 5 vezes \\
\hline 11 & 23 & 18 & 5 & 3 & 10 \\
$(15,7 \%)$ & $(32,9 \%)$ & $(25,7 \%)$ & $(7,1 \%)$ & $(4,3 \%)$ & $(14,3 \%)$ \\
\hline
\end{tabular}

Em relação ao Gráfico 10-A, que relaciona a freqüência de uso de empréstimos pelos isseis com o seu tempo de permanência no Japão por ocasião do retorno temporário, podemos constatar que a freqüência é mais alta com referência aos informantes que jamais retornaram ao Japão. Notamos também que, dentro do período de um ano, quanto mais longa a permanência no Japão menor é a ocorrência do empréstimo. Passando desse limite, a frequiência torna a aumentar, embora não chegue a atingir o patamar dos que nunca retornaram ao Japão. Dessarte, a equação "quanto maior o tempo de permanência no Japão, menor a ocorrência do empréstimo" não se fundamenta. 
Em relação ao Gráfico 10-B, que relaciona a freqüência do uso de empréstimos com o número de visitas ao Japão, fica comprovada a equação "quanto mais freqüentes as visitas ao Japão, menor a ocorrência de uso de empréstimos"

Esses resultados permitem-nos concluir que:

1. os isseis que nunca retornaram ao Japão apresentam alta frequiência de uso de empréstimos, por não se exporem há um tempo considerável a ambientes de uso exclusivo da língua japonesa. Assim sendo, as lexias do português acabam sendo por eles inconscientemente incorporadas como sendo da língua japonesa;

2. o número de visitas ao Japão é mais significativo no uso de empréstimos do que o tempo de permanência naquele país, o que nos leva à hipótese de que a freqüente circulação por ambientes de uso exclusivo de uma língua aumenta a capacidade de discernimento de cada uma delas e, conseqüentemente, o seu uso diferenciado, o que se reflete na diminuição da frequiência de uso de empréstimos.

Até aqui, realizamos a análise da freqüência de uso de empréstimos lexicais, consoante cada um dos fatores sociais estabelecidos. Entretanto, como ficou demonstrado nessa análise, o que determina a freqüência de uso de empréstimos não é cada um desses fatores sociais isoladamente e sim a sua inter-relação. Para podermos analisar essa situação, torna-se-nos necessário recorrer à análise multivariável. Como a realização de uma análise desse tipo requer dados volumosos, lamentavelmente neste estudo não nos foi possível realizá-la. Por isso, procedemos, na medida do possível, à análise conjugada de dois fatores que julgamos relativamente influentes na freqüência do uso de empréstimos, como são os casos dos Gráficos 9-A e 9-B do item 9.

Para o estudo estatístico dos fatores sociais no empréstimo lexical, aplicamos a regressão de Poisson (cf. Tabela 11), em que o número de empréstimos é escrito como a soma dos efeitos de sexo, idade atual, idade da chegada no Brasil, profissão, escolaridade, proficiência em português, uso do japonês na vida diária, número de visitas ao Japão e tempo de permanência no Japão quando em visita, conforme descrito anteriormente. $\mathrm{O}$ tempo de permanência do issei em solo brasileiro não entrou no nosso modelo, por ser a diferença entre a sua idade atual e a sua idade na ocasião da chegada no Brasil.

Assim sendo, a inclusão desse fator seria redundante, além de a possibilidade de vir a trazer problemas ao ajuste. $\mathrm{O}$ ajuste desse modelo revelou que o sexo, a idade na ocasião da chegada ao Brasil, a idade atual e o tempo de permanência ou visitas ao Japão não têm impactos significativos no empréstimo lexical do português ( $p=0,89, p$ $=0,73, p=0,95, p=0,99$, respectivamente). Estatisticamente observando, a profissão tem o maior índice $(\mathrm{p}<0,01)$. Os profissionais qualificados são os que fazem menos uso de empréstimos, seguidos do grupo de isseis denominado "outros", depois dos agricultores e, por último, dos comerciantes. O nível de escolaridade dos isseis também tem efeito significativo $(p<0,001)$, sendo que os informantes com nível fundamental recorrem mais aos empréstimos, seguidos dos que têm nível médio e, finalmente, dos de nível de escolaridade superior. A proficiência dos isseis no português também revelou efeito significativo do ponto de vista estatístico $(p<0,01)$. Os informantes com boa proficiência no português são os que mais usam empréstimos, seguidos daqueles cuja 
Tabela 11

Análise do Parâmetro Estimado

\begin{tabular}{|c|c|c|c|c|c|c|}
\hline \multicolumn{2}{|l|}{ Parameter } & $\mathrm{DF}$ & Estimate & Std Err & Chisquare & $\operatorname{Pr}>\mathrm{Ch} i$ \\
\hline \multicolumn{2}{|l|}{ INTERCEPT } & 1 & 1.2991 & 0.5221 & 6.1913 & 0.0128 \\
\hline \multirow[t]{2}{*}{ SEXO } & inino & 1 & -0.0137 & 0.1003 & 0.0188 & 0.8911 \\
\hline & culino & 0 & 0.0000 & 0.0000 & & \\
\hline \multicolumn{2}{|l|}{ IDADE } & 1 & -0.0033 & 0.0596 & 0.0030 & 0.9563 \\
\hline \multicolumn{2}{|c|}{ IDADE DE CHEGADA } & 1 & 0.0209 & 0.0596 & 0.1230 & 0.7258 \\
\hline \multirow[t]{4}{*}{ PROFISSÃO } & ricultor & 1 & 0.4575 & 0.1593 & 8.2494 & 0.0041 \\
\hline & merciante & 1 & 0.6970 & 0.1993 & 12.2238 & 00005 \\
\hline & Qualificado & 1 & -0.7493 & 0.2612 & 8.2304 & 0.0041 \\
\hline & tros & 0 & 0.0000 & 0.0000 & & \\
\hline \multirow[t]{4}{*}{ ESCOLARIDADE } & Primário & 1 & 0.8987 & 0.2339 & 14.7639 & 0.0001 \\
\hline & Ginásio & 1 & 0.8025 & 0.2177 & 14.3678 & 0.0002 \\
\hline & Colegial & 1 & 0.6159 & 0.2012 & 9.3704 & 0.0022 \\
\hline & Superior & 0 & 0.0000 & 0.0000 & & \\
\hline \multirow[t]{5}{*}{ PORTUGUÊS } & xcelente & 1 & 0.1646 & 0.2592 & 0.4035 & 0.5253 \\
\hline & $\mathrm{om}$ & 1 & 1.5163 & 0.2562 & 35.0194 & 0.0001 \\
\hline & édio & 1 & 0.1086 & 0.1858 & 0.3415 & 0.5590 \\
\hline & raco & 1 & 0.5188 & 0.1894 & 7.5080 & 0.0061 \\
\hline & 1lo & 0 & 0.0000 & 0.0000 & & \\
\hline \multicolumn{2}{|c|}{ USO DE JAPONÊS } & 1 & -0.0135 & 0.0024 & 32.2514 & 0.0001 \\
\hline \multicolumn{2}{|c|}{ TEMPO DE VISITA AO J } & 1 & 0.0011 & 0.0606 & 0.0003 & 0.9861 \\
\hline \multicolumn{2}{|c|}{ NÚMERO DE VISITAS AO J } & 1 & -0.0101 & 00043 & 5.6565 & 0.0174 \\
\hline \multicolumn{2}{|l|}{ SCALE } & 0 & 1.0000 & 0.0000 & & \\
\hline
\end{tabular}

NOTE: The scale parameter was held fixed.

proficiência foi por nós qualificada como fraca. Estatisticamente, não há diferença nas demais categorias, excelente, média e nula. A proporção de utilização da língua japonesa na vida diária dos isseis também mostrou-se estatisticamente relevante $(\mathrm{p}<0,01)$. Observamos que o uso de empréstimos aumenta na medida em que diminui a proporção do uso do japonês. Finalmente, a análise evidenciou que o número de visitas ao Japão é significativo $(\mathrm{p}<0,01)$ no uso de empréstimos da língua portuguesa do Brasil: quanto mais visitas ao Japão feitas pelo issei, menor é o número de uso de empréstimos.

Para verificar a proporção da influência que cada um desses fatores exerce na freqüência de uso de empréstimos pelos isseis, entabulamos os dados aqui obtidos com 
os resultados analisados nos itens (1) a (10) e chegamos às seguintes conclusões. $\mathrm{O}$ primeiro fator social que parece exercer maior influência na frequiência de uso de empréstimos lexicais do português brasileiro no japonês falado pelos isseis é a proporção do uso diário da língua japonesa ou portuguesa. Quanto mais alto o grau de contato com o português e a conseqüente diminuição do uso do japonês, maior a freqüência de uso de empréstimos lexicais. Assim, os comerciantes que usam o português do Brasil para as suas transações recorrem ao empréstimo lexical por hábito adquirido, mesmo quando falam o japonês. Outros isseis, que usam freqüentemente o japonês e mantêm menos contato com a língua portuguesa, como no caso dos agricultores, apresentam uma frequiência mais baixa de uso de empréstimos.

Em seguida, vem o fator proficiência dos isseis no português brasileiro, que se refere ao nível de escolaridade. Quanto melhor o desempenho do issei no português, maior é o uso de empréstimos lexicais. Os informantes que apresentaram melhor desempenho na língua portuguesa do Brasil possuem nível de escolaridade mais alto.

Concluímos, dessa feita, que os fatores nível de escolaridade, profissão, proficiência no português brasileiro e proporção de uso do japonês e do português estão interligados. $\mathrm{O}$ que nos chama a atenção é a queda abrupta que se verifica na curva de freqüência de uso de empréstimos nos Gráficos 7, 8, 9. Por um lado, o índice de freqüência cai consideravelmente com relação aos informantes isseis com pequena proporção de uso do japonês; por outro lado, o índice de frequiência aumenta no caso dos informantes proficientes no português e com alto nível de escolaridade. Em relação aos isseis que usam muito pouco o japonês no seu cotidiano, podemos atribuir a causa possível do baixo índice de frequiência de empréstimos ao esforço que fazem conscientemente para evitar o uso de empréstimos e à sua tentativa de falar o japonês padrão, o que por vezes está associado ao seu limitado domínio do japonês. Contudo, ao fazermos uma análise global incluindo os informantes com alto grau de proficiência em português e alto nível de escolaridade, verificamos que os isseis que ocupam profissões que exigem qualificação são os mais representativos.

Dessa observação, fica-nos evidente que esses profissionais, apesar de serem altamente proficientes no português brasileiro e usarem a língua portuguesa amiúde no seu cotidiano, apresentam baixo nível de freqüência de uso de empréstimos - e esses informantes também possuem um alto nível de escolaridade.

Muitos sociolingüistas (Bernstein, 1974; Labov, 1972; Trudgill, 1975; Poplack, Sankoff e Miller, 1988) têm a classe social como parâmetro nos seus estudos e observam a variação lingüística de acordo com ela. A pesquisa realizada por Poplack, Sankoff e Miller (1988) com francófones do Canadá comprovou que a frequiência de uso de empréstimos lexicais e a classe social estão intimamente relacionadas e que a classe operária apresenta maior freqüência de uso desses empréstimos do que o grupo de pessoas pertencentes à classe média. Porém, o modo pelo qual os pesquisadores definem as classes sociais difere. Há autores que utilizam a renda e o valor do imóvel residencial como parâmetro do fator econômico. No presente estudo, não levamos em consideração o fator econômico, porque, no Brasil, o nível de escolaridade nem sempre está relacionado com o poder econômico. Como exemplo, podemos citar os professores, os médicos de hospitais públicos e os funcionários locais de embaixadas estrangeiras, que pertencem 
à categoria de profissionais qualificados, mas recebem um parco salário. Assim sendo, torna-se difícil relacionar o fator econômico com a classe social no que se refere ao Brasil. Por isso, optamos por não enquadrar os profissionais qualificados como pertencentes à classe social elevada. A causa da baixa frequiência de uso de empréstimos por esses profissionais está mais no seu alto nível de conscientização lingüística do que na sua classe social. A rigor, a capacidade que os isseis possuem de usar de forma distinta as duas línguas, sem misturá-las, é o que faz com que a frequiência de uso de empréstimos seja baixa.

Em relação à influência da capacidade de uso diferenciado das duas línguas no grau de freqüência de uso de empréstimos lexicais, lembramos que quanto mais o issei transita alternadamente por ambientes exclusivamente de língua japonesa e por outro, no caso, de língua portuguesa, mais aumenta a sua capacidade de uso distinto das duas línguas envolvidas e, em conseqüência, menor é a sua freqüência de uso de empréstimos.

Comprovamos que os fatores sexo, idade, ano de chegada no Brasil e tempo de permanência no Brasil, ao contrário do que supúnhamos, não exercem influências muito significativas na freqüência de uso de empréstimos lexicais pelos isseis. A variação da freqüência de uso de empréstimos, observada no gráfico 4 (idade em que ingressou no Brasil), a nosso ver, deve ser analisado em relação à proficiência no português ou à proporção que o uso do português ocupa na vida diária do informante. Observamos que os isseis usam com parcimônia os empréstimos lexicais quando apresentam uma idade muito elevada ou vivem em um ambiente de pouco contato com o português brasileiro.

Neste estudo, a área escolhida para amostragem, para o levantamento de dados, foi o Distrito Federal (DF), cuja capital é a cidade de Brasília, que também é a capital da República Federativa do Brasil. O DF tem recebido migrantes nikkei provenientes de todas as regiões brasileiras e, por isso, ali é-nos possível obter informações acerca da comunidade nipo-brasileira em geral, dos isseis que moram em núcleos rurais, dos que residem na zona urbana das cidades do DF, das profissões que ocupam etc. Além disso, no DF existem numerosas associações nikkei ${ }^{4}$

Existe a possibilidade de que os resultados aqui apresentados sejam reflexo da tendência geral do japonês falado pelos isseis no Brasil, constituindo essa variante um paradigma da realidade do empréstimo lexical do português brasileiro ao japonês.

Como visto até aqui, o presente estudo comprova que a freqüência de uso de empréstimos lexicais do português brasileiro no japonês falado pelos isseis é determinada pelos diversos fatores sociais que se encontram intrincados entre si.

\section{Bibliografia}

AZUMA, Shôji. Shakai gengogaku nyûmon (Introdução à Socioligüística). Tokyo, Kenkyûsha Shuppan, 1997.

BERNSTEIN, Brasil. Class, codes and control. 2. ed. London, Routhdge \& Kegan Paul, 1974.

KRASHEN, Stephen D.; TERRELl, Tracy D. Nachuraru-apurôchi no susume. [The natural approach: language acquistion in the classroom]. Trad. FUJIMORI, Kazuko. Tokyo, Taishûkan Shoten, 1986.

4. Nikkei: imigrantes japoneses e seus descendentes. 
LABOV, William. Sociolinguistic patterns. Pennsylvania, University of Pennsylvania Press, 1972.

NAKAMURA, Masaru; KANEKO, Yoshiaki; KIKUCHI, Akira. Seisei bunpô no kiso: genri to paramitâ no apurôchi (Fundamento da Gramática Gerativa: Approach de Princípio e Parâmetro). 11. ed. Tokyo, Kenkyûsha, 1989.

NAKAO, Toshio; HiBIYA, Junko; HATTORI, Noriko. Shakai gengogaku gairon (Teoria da Sociolingüística). Tokyo, Kuroshio Shuppan, 1997.

POPLACK, Shana; SANKOFF, David. "Borrowing: the synchrony of integration" Linguistics, Amsterdam, n.22, pp.99-135, 1984.

POPLACK, Shana; SANKOFF, David; MILlER, Christopher. "The social correlates and linguistic processes of lexical borrowing and assimilation" Linguistics, Amsterdam, n.26, pp.47104, 1988.

Romaine, Suzanne. Bilingualism. Oxford, Basil Blackwell, 1989.

SAVILLE-TROIKE, Muriel. The ethnography of communication. 2. ed., Oxford, Basil Blackwell, 1984.

SUZUKI, Teiiti. Burajiru no nikkei imin (The Japanese immigrants in Brazil). Tokyo, Tokyo Daigaku Shuppan, 1964.

TRUDGILL, Peter. Sociolinguistics: an introduction. Middlesex, Penguin Books, 1975.

\section{GRÁFICOS}

Gráfico 1. Sexo

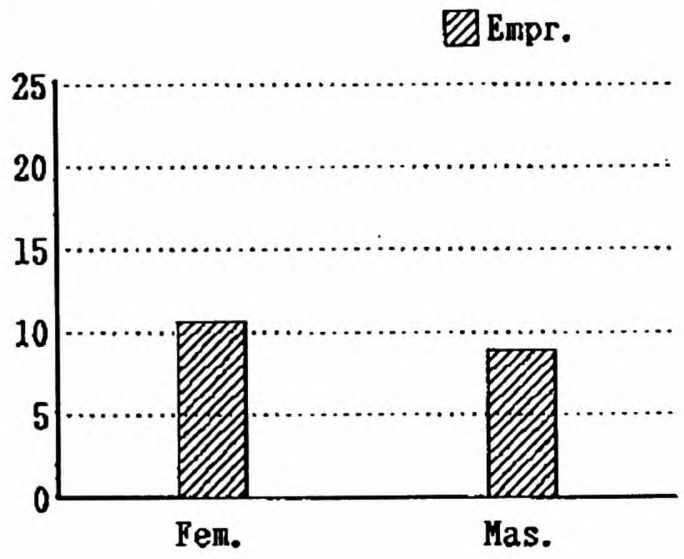

Gráfico 2. Idade

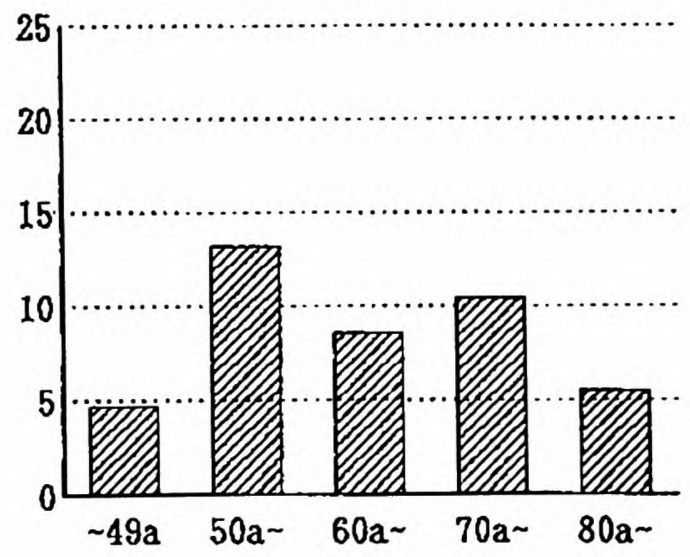


Gráfico 3. Ano de Ingresso no Brasil

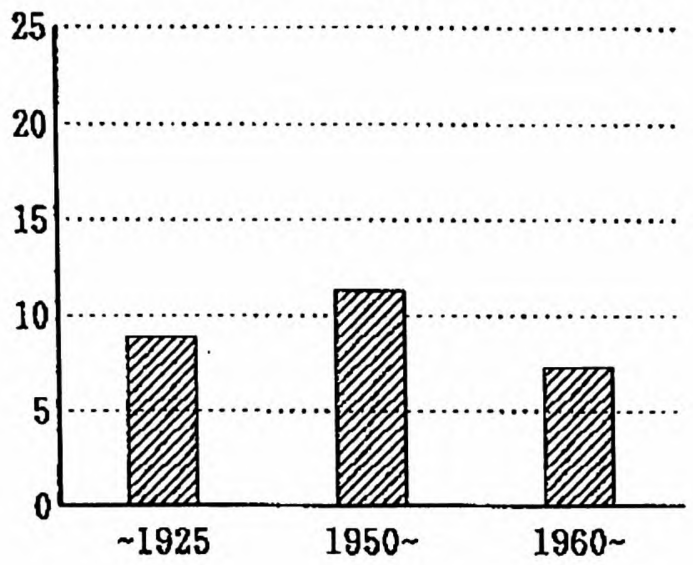

Gráfico 5. Tempo de Permanência no Brasil

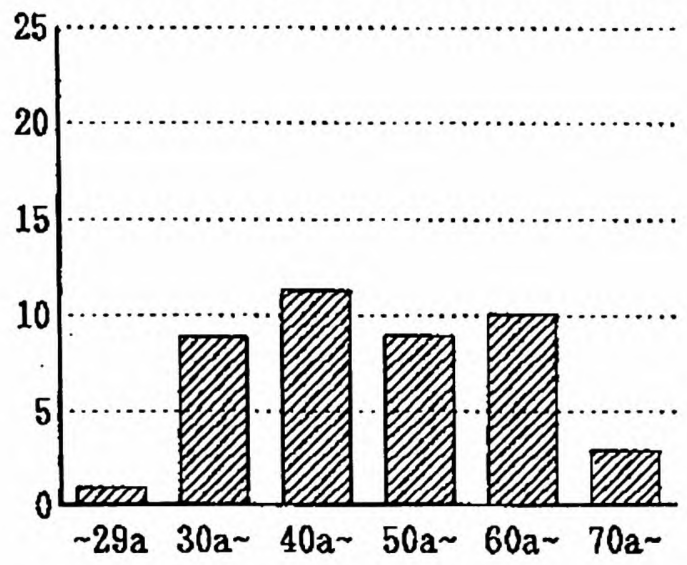

Gráfico 7. Escolaridade

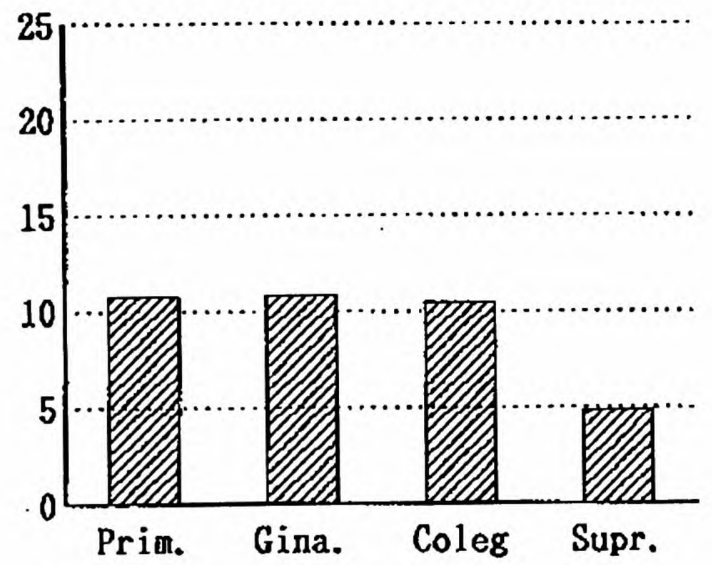

Gráfico 4. Idade ao Ingressar no Brasil

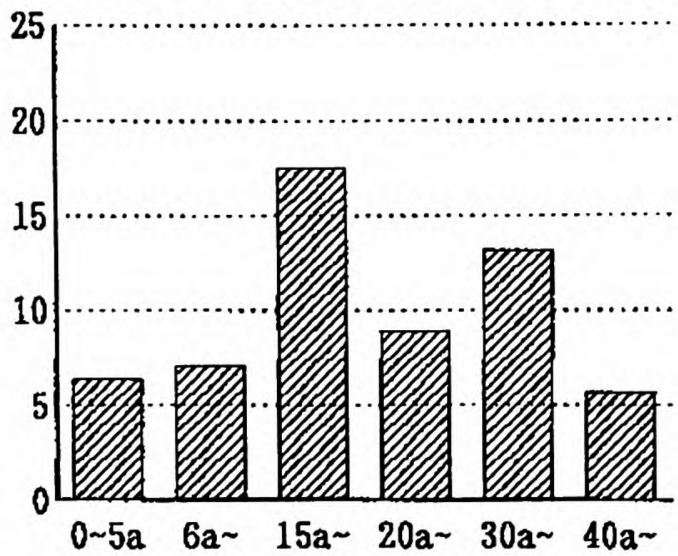

Gráfico 6. Profissão

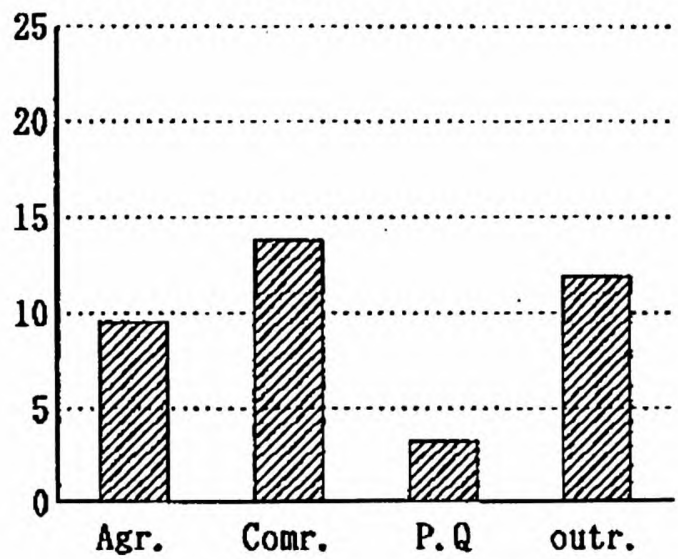

Gráfico 8. Proficiência em Português

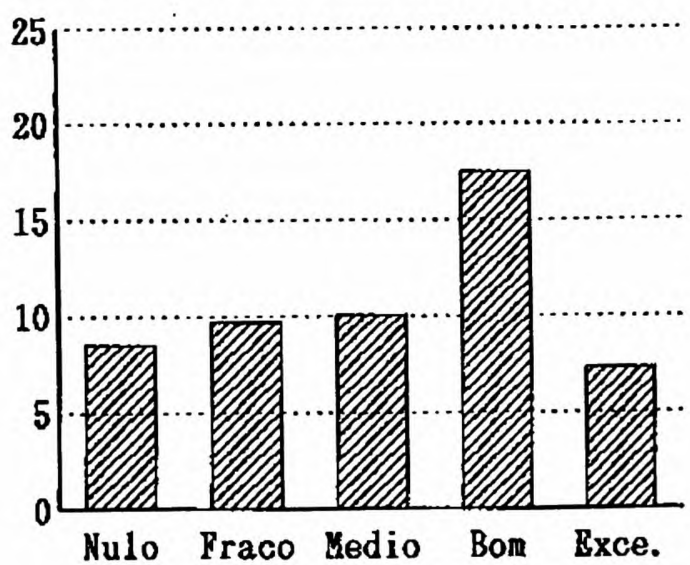


Gráfico 9-A. Proporção da Língua Japonesa na Vida Diária

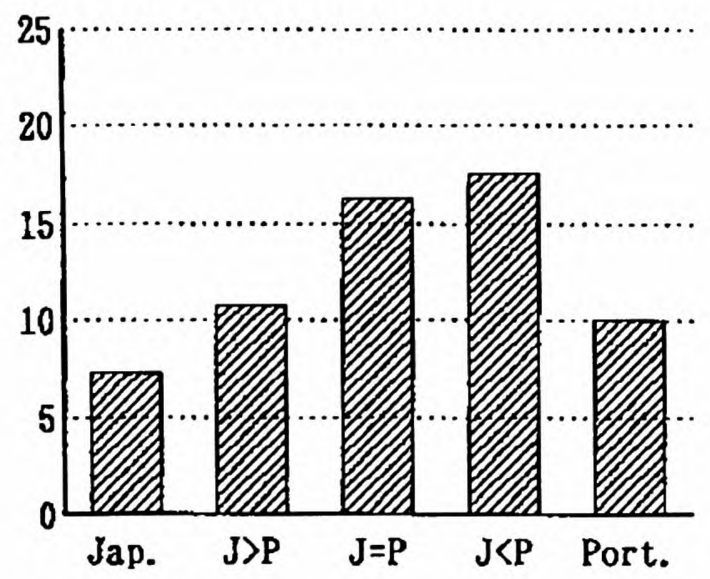

Gráfico 10-A. Tempo de Visitas no Japão

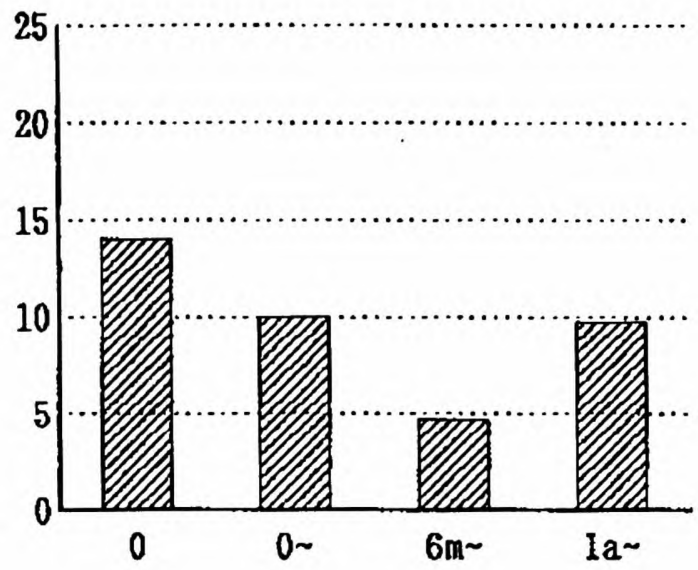

Gráfico 9-B. Proporção da Língua Japonesa na Vida Diária

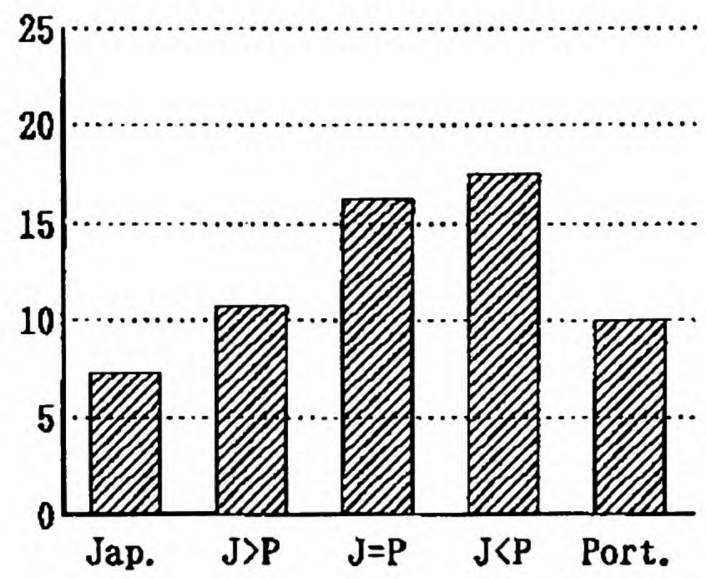

Gráfico 10-B. Número de Visitas ao Japão

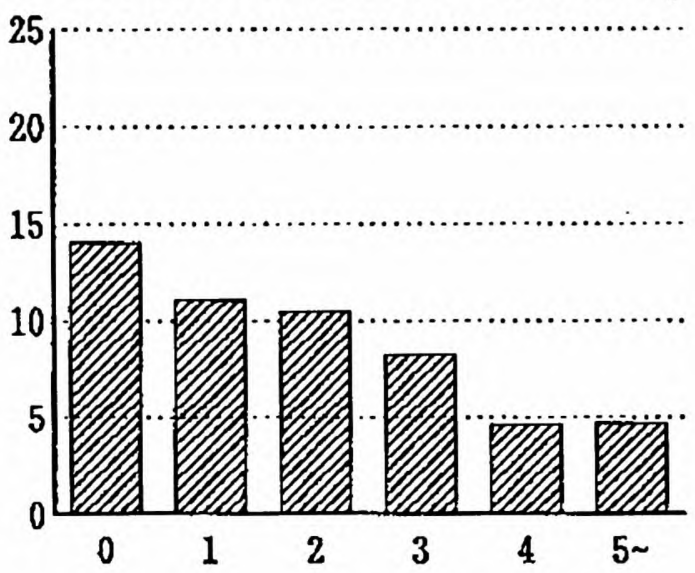

